\title{
The use of Key Performance Indicator in Malaysian Government-Linked Company
}

\author{
Noor Raudhiah Abu Bakar \\ Selangor International Islamic University College \\ (KUIS), \\ 43000 Kajang, Selangor, Malaysia \\ raudhiah@kuis.edu.my \\ Dr. Mazlina Mustapha \\ Fakulti Ekonomi dan Pengurusan \\ Universiti Putra Malaysia \\ mazlina@econ.upm.edu.my
}

\author{
Profesor Madya Dr. Nor Aziah Abu Kasim \\ Fakulti Ekonomi dan Pengurusan \\ Universiti Putra Malaysia \\ noraziah@econ.upm.edu.my \\ Dr. Rozita Amiruddin \\ Fakulti Pengurusan Perniagaan \\ Universiti Kebangsaan Malaysia \\ rozita@ukm.edu.my
}

\begin{abstract}
Government-linked companies (GLCs) play an important role in the development of the Malaysian economy. To enhance performance in GLCs, Malaysian government introduced GLC Transformation program. The first initiative in GLCT is to intensifying performance management systems. The GLC Blue-Book as a guidance in intensifying performance management and include suggested key performance indicator (KPI). However, the use of KPI always become an issues in the companies. The purpose of this article is to examine the use of KPI in one of Malaysian Government-Linked Companies. A qualitative case-study approach is applied using semistructured interviews, participant observations and analysis of documents. This article illustrates the criteria of KPI linked with planning, information flow, linked with performance evaluation and control employees behavior at the organizational level based on the perceptions of the multi-level of employees from different departments. This article concludes the use of KPI linked with the planning, good information flow, linked with performance evaluation and influences the behavior and performance of employees.
\end{abstract}

Keywords-Key Performance Indicator; Performance Management; Balanced Scorecard; GLCs; Performance Measurement

\section{INTRODUCTION}

Malaysia is now at its crucial time of attaining Vision 2020, which is to become a developed country by 2020 . The Malaysian Government posits that Government-linked companies (hereafter, GLCs) can play a crucial role in developing the economy as well as achieve the goal of industrialising the nation by 2020 . To enhance performance in GLCs, Government-Linked Companies Transformation Program (GLCT) was introduced in 2004.

The objective of GLCT is to catalyse change in GLCs in order to transform them into high-performance entities (PCG, 2008). The first incentive in GLCT program that has been implemented is "intensifying performance management". Within this incentive, "GLC Blue-book" has been introduced to provide more comprehensive guidelines on the implementation of performance management in GLCs (PCG, 2005).

GLC Blue-book provide the guidelines for KPIs designs and a performance-linked compensation (Ministry of Finance, 2004). The main objectives are to ensure that GLCs (i) focus on key success factors; (ii) attract, motivate and retain professional talent; (iii) measure performance objectively; and (iv) link rewards and performance. Overall, the KPI Design species that the selected KPIs must be objective, balanced and benchmarked against the industry. The recent interest in KPIs for GLCs is seen as a solution to strengthen performance (Mansor, Bahari, \& Justine, 2008). This article focuses on the use of KPI among employees in one of the main Malaysian GLCs.

The KPI used always linked to the Balanced Scorecard (BSC). KPI is the main tool used in BSC is widely adopted by Malaysian organisations (Ayedh, 2007) and Malaysian GLCs. While the GLC Blue-book is a useful guide, it requires tool such as BSC to complement its performance management. According to Zin and Sulaiman (2011), BSC would be the most suitable tool to support GLC Blue-book. The case organization for this study which is MMG Berhad (fixtures name) is using BSC as their performance management and the BSC used include KPI as a main tools.

This paper has two main aims. First, it aims to provide evidence of KPI use within GLC. This will broaden the understanding of how the KPI operates in these organisations and hence enrich the BSC literature. Second, the paper aims to examine the effect of KPI use to employees' behavior and performance.

To pursue the aims of the study, a case study of a large Malaysian GLCs was conducted over six month period. Semi-structured interviews, organisational documents and observation were used in the data collection process.

The findings reveal that the KPI has been used as a systematic performance management system in the case organisation. They have an organise system that linked the 
strategy to the KPI that have been used by all staff. However, the system has a flaw when it linked to the performance evaluation system.

This paper is organised as follows. The next section provides a literature review, which begins with a discussion on the studies of BSC in GLCs and concluding with the BSC as a performance management system. This is followed by a section on the research method and design of the study. The subsequent section focuses on the analysis of the case study, including the background of case organisation, the implementation of BSC and the twelve themes in performance management framework. This is followed by the discussion and conclusion sections.

\section{LITERATURE REVIEW}

The literature review is divided into two subsections. The two subsections are the use of KPI and balanced scorecard in GLCs.

\section{A. The use of KPI}

The KPI can be defined as a tool to monitor the degree of achievement of the performance levels defined by key performance areas (Verzola et al., 2009). Goodpasture (2003) added KPI is a tool for systematically delivering measurements and key success factors is well established in the management literature.

The appropriate KPI need to be determined in order to measure performance (Cox et al., 2003; Enos, 2000; Verweire and Berghe, 2004). A set of structured KPIs, thereafter helps in tracking the desired performance and aids in managerial decisions (Crager et al., 2005).

The purpose of the KPI is to enable quantifiable measurements that reflect the critical success factors of an organization (Bose, 2006; Chan and Chan, 2004; Beatham et al., 2005). Important steps in developing KPIs is to translate BSC into the CSFs and formed into a coherent set of key performance measures (KPIs) (Coakes, 2003). The use of KPI always linked to the Balanced Scorecard use and widely adopted by Malaysian GLCs. The next subsections discussed on BSC in GLCs.

\section{B. Balanced Scorecard in Government-Linked Companies}

This study chooses Malaysian GLCs as the sample of study due to importance of GLCs in Malaysian economy, the problems faced by Malaysian GLCs and unique characteristics that differentiate Malaysian GLCs from private and public sector companies, NGO and GLCs in other countries. In general, GLCs are unique because they have a direct link to the government via shareholding and have both social and national obligations.

GLCs can be defined as those companies in which some shares are owned by government (Feng, Sun, \& Tong, 2004). GLCs are also known as state-owned enterprises (SOEs) and non-financial public enterprises (NFPEs) (NEAC, 2010). Studies on BSC in GLCs include Northcott and Smith (2011), Sundin, Granlund, and Brown (2010), Norhayati and
Siti-Nabiha (2009), James (2009), Jazayeri and Scapens (2008), Mansor et al., (2008), Andon, Baxter and Chua (2007) and Othman, Domil, Senik, Abdullah, \& Hamzah (2006).

The earlier study on implementation of BSC in GLCs showed a difficulty to implement. For example, study by Andon et al. (2007) which intends to manufacture performance measurement includes BSC in Australasian telecommunications organisation. However, the implementation of BSC was failed due to the difficulty in producing KPI.

Different with the study by Northcott and Smith (2011) which shows that BSC provides a potentially useful tool for evaluating the performance of boards of directors. They draw on the perspectives and experiences of New Zealand board members to propose a balanced scorecard (BSC) for use in measuring and managing the performance of boards. They interviews 35 board members were elicited from New Zealand public companies (PLCs) and New Zealand GLCs. The finding shows New Zealand board members see the KPI behavioural measures of board performance as generally more useful than operational and financial measures. .Their study also recognises the importance of including subjective measures, rather than focusing on readily quantifiable measures that board members perceive as less informative.

The successful implementation of BSC in GLCs is also proven by Jazayeri and Scapens (2008). They explored the evolution of BSC as performance measurement tool in GLCs in United Kingdom. The BSC used in organisation emphasize on the importance of coherence rather than causeand-effect relationships. Furthermore, the BCS was not simply designed and then implemented; instead it evolved over an extended period of time. BSC has been used as a tool to enable strategy to emerge from within the organisation. They believe that BSC has made an important contribution to the recent success of the company under consideration.

One outstanding research work is of Sundin et al. (2010), which investigates how multiple and competing objectives are managed within an organisation, and the role that the BSC plays in balancing organisational objectives in GLCs in Australia. The study adopts an exploratory case study approach to understand how the BSC is used in management decision and control processes to assist with the balancing of objectives. The results of the study demonstrate that BSC has the potential to help in making trade-offs and balancing objectives, but there are certain requirements for this to succeed.

Study by James (2009) highlight the influences of new institutional sociology (NIS) theory in examines the impact of national competition policy on the design and implementation of a balanced scorecard (BSC) in one of Australian GLC. James (2009) highlights the importance of the deliberation of both rational analytical approaches and legitimacy as a fundamental accompaniment to isomorphism in the continuing development of accounting systems in the GLC. 
The study by Sundin et al. (2010), James (2009) and Jazayeri and Scapens (2008) show that the BSC used in organisation should be altered according to the needs and conditions of the organisations especially GLCs which have control by government. However GLCs in other countries are expected to be different as compared to GLCs in Malaysia. Malaysian GLCs have evolved from privatisation program and now they undergo the GLC transformation program.

In Malaysia, many GLCs (e.g. TELEKOM Berhad, PETRONAS Berhad, and SYABAS) are using BSC in their organisations. However, there is limited research on the implementation of BSC in Malaysian GLCs. Norhayati and Siti-Nabiha (2009) study the process of changes of performance management system in one GLC company in Malaysia and that company is using BSC as a new performance management. Their study finds out that the BSC did not really change the way organisational members view and do things in the organisation.

Norhayati and Siti-Nabiha (2009) only study the process of changes in performance management using Laughlin framework in order to evaluate the use of BSC as performance management mechanism. Their study focuses more on the process of management change through institutional theory. The study shows that the intention to institutionalise a new practice may not materialise if there are not enough forces to support the change. The adoption of $\mathrm{BSC}$ as a new performance management practice may be due to isomorphic pressures to mimic other organisations in the same environmental field leading to ceremonial adoption of the practice.

Another study by Othman et al. (2006), examines the implementation of BSC in a telecommunication company in Malaysia and also one of the GLCs. Their study discovers that the company did not have causal model and strategy map, which leads to under-exploited use of BSC. Othman et al. (2006) also identify the problems of using BSC that arise as a result of some of the limitations of the BSC. The problems comprise of difficulty in developing a causal model of its strategy and non-financial measures. The problems also came from employees whereby managers tend to ignore the dynamics of the external environment in planning the implementation of their strategy.

In summary, the studies on use of BSC in Malaysian GLCs show negative results. Othman et al. (2006) and Norhayati and Siti-Nabiha (2009) argue that the BSC did not increase the performance in GLCs. The use of BSC did not change the attitude of the employees and culture of the organisation (Norhayati and Siti-Nabiha, 2009). The BSC used were not fully functional because it did not include the causal model and strategy map (Othman, 2006). Othman et al. (2006) and Norhayati and Siti-Nabiha (2009) argue that BSC is not suitable for Malaysian organisations because of high power distance in Malaysian culture.

The studies in Malaysian GLCs related to performance management were conducted from 2004 until 2007. At that time, GLC Transformation (GLCT) program was just introduced in GLCs and the result of those studies reveals the resistance of the employees. A possible reason is that the GLCs Transformation Manual had just been introduced in 2005 and it would probably have taken a few years for the operational enhancement initiatives outlined in the Manual to take effect. To date, the GLCT program is in the final stage and the result of the GLCT program may change the result of the study.

In contrast with Othman et al. (2006) and Norhayati and SitiNabiha (2009), a study carried out by Zin and Sulaiman (2010) argues that BSC should be used by GLCs to strengthen the GLCT program. The BSC will eventually help GLCs to improve their performance. In addition, study by Mansor et al. (2008) discover managers in Malaysian GLCs felt that BSC can improve performance in GLCs. Their study discusses the characteristics of strategy-based KPIs to promote balanced performance for long-term sustainability

Although there are many studies concerning the implementation of BSC, but studies on implementation of BSC as a performance management especially in GLCs are limited. Most of the studies also linked the problems in BSC with the KPI use in the organisation.

\section{RESEARCH METHODOLOGY AND DESCRIPTION OF THE CASE-STUDY ORGANISATION}

In this paper, we examine the use of KPI in one of Malaysian GLCs named MMG Berhad (fixtures name). The rationale for applying a single case-study approach is to be able to capture rich and holistic material which can be used as comparison to previous studies (Sharma, Lawrence, \& Lowe, 2010). The study was performed during the period Jun 2013 until April 2014. In total, 20 interviews and observations of place work were carried out. The observations meant during their timework. The interviews were semi-structural, lasting about one hour each. Both men (7) and women (13) were interviewed. In total, two officers at non-executive level, six executive level, nine managers and three assistant general managers were interviewed. All interviewees have been presented with no names to ensure research participant anonymity. Appendix 1 shows a list of interviewees, their positions, attached department, job description and their involvement in BSC.

The permission to conduct research from the case organisation (MMG) was obtained in 2013. The MMG journey began when it became the Malayan Department in 1946. In 1964, MMG change into Jabatan Malaysia. MMG undergone privatisation on 1987 became Syarikat Malaysia Berhad. MMG listed on the Main Board of Bursa Malaysia.

MMG has literally built the country's utilities infrastructure. MMG has been chosen as a case organisation because of its status as main Malaysian GLCs and have been undergo GLCT program. MMG also being chosen because of the organisation is a main player of Malaysian economics.

In 2012, MMG have shown an excellent performance in financial and become one of the main champion leader in 
providing one of main utilities in Malaysia. The real names of the organisation are not disclosed for reasons of confidentiality. The actual names of the programmes have also been replaced with fictitious names.

\section{ANALYSIS OF RESEARCH MATERIALS}

The following analysis collates the observations from interviews conducted and organizational documents. The analysis is divided into two: (1) the use of KPI in MMG, and (2) the influence of KPI to employees behavior and performance.

\section{A. The use of KPI in $M M G$}

The use of KPI in MMG started when MMG adopt BSC since 1990s. They choose to adopt BSC after they have been privatisation because they believe that BSC can improve their performance. They also believed that the BSC can give them competitive advantage. The popularity of BSC as a good system also influenced them to adopt BSC. They decision on adopting and using BSC also influenced by the Malaysian government.

Start by 2005-2007, the BSC have been improved and extensively used by the MMG. The used of BSC in MMG is also being influenced by the Blue-book (GLCT). MMG produce one book name Over Blue (fixtures name) which have integrate $\mathrm{BSC}$ with the Blue-book.

Over Blue give guidance to the employees in MMG on how to used BSC effectively. This book has nine chapters include introduction, strategy map, alignment, cascading and health check. This book is also similar with the book produced by Kaplan and Norton (2000). The BSC used in MMG also have four items which is similar with Kaplan and Norton (1992, 1996, 2000).

The implementation of BSC in MMG starts from developing business Plan. Business Plan for MMG is 3 years business planning set by MMG. Normally business plan starts to be developed in June until December. In producing business plan, every department will have to identify what to achieve. There is a bottom up and top down information flow in the process of developing business plan.

Then, from business plan, the group strategy and planning will come out with the strategic objectives for the year of the company based on MMG Business Plan. Normally there are 10 to 12 strategic objectives for each year. Balanced Scorecard will match together all information and align with strategic objectives.

Next, the strategic objectives will be presented to the first tier for discussion and approval. After approval, the KPI will be released based on strategic objectives and communicated through second tiers and below. The BSC is cascade down to all executives in every OPCOS and subsidiary and aligned accordingly. BSC is expected to be communicated among MMG employees by first quarter every year.

The KPIs used in MMG can be divided into three: (1) Shared KPI, (2) Common KPI and (3) Functional KPI. Shared KPI is cascade to lower tier in line with job function which enables direct contribution or influences. Example of shared $\mathrm{KPI}$ is group revenue. Common KPI cascade to lower tier as long the KPI can be measured by independent body. Example of common KPI is Employee Engagement Index (EEI). Functional KPI is to be identified to support upper tier's KPIs. This KPI are other than shared and common KPIs relate to the lower tier's job functions.

At the end of each year, the performance of the employees will be evaluated based on their achievement of KPI, target and budget. Their current performance will be evaluated accordingly to group and individual achievement. The result will affect the bonus received and increment for the year.

The overall performance of MMG will be review and the strategic objectives will be identified for the next year. The implementation of BSC in MMG will also be health check by internal audit each year for continue improvement after completion cascade or when required. The next subsection will be discuss the use of KPI based on the the usefulness of KPI: (1) linked with the planning, vision, mission, objectives and strategies, (2) cascading, information flows (3) linked with performance evaluation and rewards and (4) used and control.

\section{Planning}

The used of KPI in MMG is linked to vision, mission and strategies and plans. The vision of MMG is to be Malaysia's leading utilities provider, embracing customer needs through innovation and execution excellence. In order to achieve their vision, the mission of MMG is they are determine to do strive towards customer service excellence and operational efficiency, enrich consumer lifestyle and experience by providing innovative new generation services, improve the performance of their business customers by providing high value information and communications solutions, deliver value for stakeholders by generating shareholder value and supporting Malaysia's growth and development. The vision and mission of the MMG have been integrated to strategic objectives of the company. From the strategic objectives, the KPI have been set and released.

It was evident from the interviews that the staffs of MMG have similar views regarding MMG vision and mission. All of them agreed that KPI used is linked to the vision and mission of MMG. One of them added that KPI used is linked to strategic objectives and alignment between departments is to support each other. One of the respondent said that every department also have they own vision and mission that linked to the main vision and vision of the organisation. In addition, one of the respondent stated that before setting the KPI, there will be a meeting between general manager and manager. In the meeting, they will decide which KPI should be added or removed follow the direction from top 
management and the KPI stated should support the function of general manager and manager. The KPI can be divided into shared and individual. Example of shared KPI is revenues. The individual KPI also can be divided into two which is core and non-core job. The core job is the main and daily routines job while the non-core job is not a main job and depends on the requirements or projects. The effect of core job is on the division especially human resources and finance department. As a whole, MMG strategies appeared to be well communicated to employee and strongly linked to KPI used.

\section{Structure and Information Flow}

Organisational structure of MMG is divided by division based on line of business (for example :consumer, SME and global). The line of business have organisational structure of MMG which is divided into 4 tiers. The first tier is CEO and BOD. The second tier is General Manager in each division. Third tier is Assistant General Manager and the fourth tier is Manager. Below fourth tier is Assistant Manager/Executive and Non-executive. The general structure of employees level is stated below by the diagram of organisational structure.

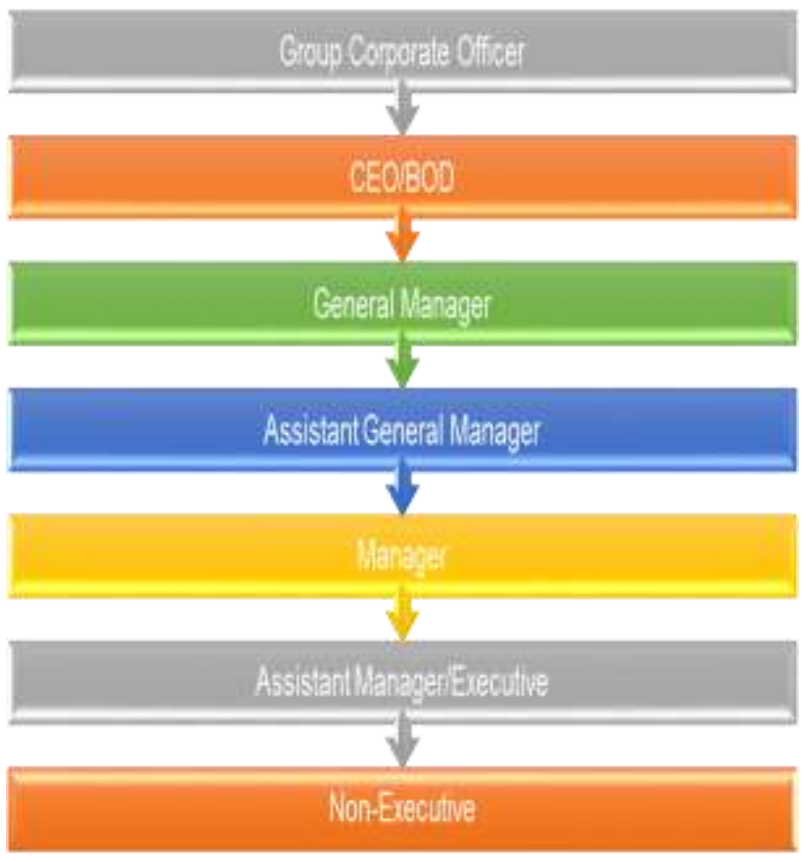

\section{Diagram 2 The level of employees in MMG}

The KPI used is followed the organisational structure. KPI is aligned and cascaded based organisational structure. Most of the interviewees said that KPI is top down but some of them argue that KPI start with down-top and then top down and some of them said depends on the situation.

In summary, all the KPI is communicate top down and bottom up. The top down communication for KPI means that from the top management the KPI is cascading down for each level emphasise on the mission and vision to be achieved but the employees also can proposed their own KPI based on their job description. The direction and guidelines are from top to bottom. The both communication resulted the combination of KPI that relevance for employees to achieve and at the same time lead to the achievement of the vision and mission of the MMG. However, one of the interviewee argue that the direction from top management difficult to negotiate and have to implement. They as a lower level have to accept even though they don't agree. In addition, one of the manager stated that manager level do not give an impact to decision made by the top management but they agree that direction from top management is for the success of the MMG.

The decision making in MMG appear to be in the middle between centralisation and decentralisation. One of the interviewee stated that It depends on the issues and how big is the budget relates to the issues. In addition, to avoid any conflict from among employees, there are guidelines to make decisions. However, some of the interviewees argue that MMG can't simply make their own decisions because of its status as GLCs and MMG is also subject to the Khazanah Berhad especially when it comes to giving the project and tender. The government does not want any company' favoritism by MMG. Khazanah Berhad also send their employees to become part of the top management in MMG. Once, Khazanah Berhad issue directions contrary to the requirements of the MMG, but MMG must follow the requirements of the Khazanah Berhad.

The budget is allocated based on units and projects. The budgets for units is controlled by Operational Expenditure (OPEX) and for projects controlled by Capital Expenditure (CAPEX) . In MMG, many employees is involved in many projects but the budgets for each projects is evaluate, analyse and determined carefully in meeting based on previous records and professional view point. The budgets for each projects also controlled eventually and perpetually by finance department. In addition, some of the projects are requirement by government, MMG have to follow as their status as GLCs.

Based on the proses of implementing BSC in MMG, the KPI are generated from strategic objective of MMG. The MMG has linked its KPI to strategy using BSC. The MMG has measure many aspects and based on the KPIs used in MMG which can be divided into three: (1) Shared KPI, (2) Common KPI and (3) Functional KPI.

Stated by the one of the employee from strategy department, level of performance in MMG is depends on department and individuals and the target is depending on the business plan and prior year performance. In addition, the target setting was clearly made to determine the appropriate budget and targets should be achieved by a project. One of the interviewee stated that the target is increasing every year but the challenges also increase. Other interviewee added:

"The key performance indicators (KPI) are difficult to achieve because price of technology is become cheaper 
because of global competition but the KPI always increase based on past performance."

One of the interviewee added that:

"...If KPI can be easily achieved, so that KPI is useless. The target setting on KPI is based on historical data. If managers want to improve their team, they have to set the target which encourages the full effort from the subordinate".

Most of the interviewees stated that the KPI need an effort to achieve it. One of them added that it also depends on the support team. In addition, the KPI can easily achieve if the process is clear and all employees give full commitment. In addition, in process of setting the KPI, the target must be reasonable and achievable by analysis the scenario. Top management also will question about why the employees choose that target and their decision are always based on fact.

One of the interviewee stated:

"The key performance measures are set based on past performance. There are a lot of aspect should be taken into the account to get the result. The problem is difficult to determine what need to be done to increase the performance. All the elements were measured such as revenue, customer satisfaction and time. However, to achieve the target, the creativity and effort is depends on the individual and these two criteria did not include in key performance measure."

It is the complexity that makes the measurement of revenues challenging. In addition, employee can proposed KPI to be achieved for their unit and top management will review. Employee should measure items in their job description to put in KPI. Sometimes, the work description and load is change so KPI also have to change accordingly. Most of the interviewees also agreed that all the important aspects of the key performance measures in MMG are measured. One of the interviewee stated:

"KPI used also very useful in assist employees to do their job. KPI also used as a guidelines and target, and for evaluate the performance. At the same time, KPI can increase the performance because with KPI, the job can be done more focus and organised."

However, one of the interviewee argue that KPI are specific and measurable and help MMG to be more successful but the employees behaviour become KPI oriented. He also stated that:

“...employees only think for their self and want to achieve their KPI only without think about other people and become selfish. Budget also become to rigid and no room left for creativity and capability. KPI also increase the unhealthy competition and work culture become worst. Commitment and attitude can be measure. MMG have 360 which provide the evaluation on behaviour but the evaluation is bias and depends on many other factors."
Stated by the one of the employee from strategy department, level of performance in MMG is depends on department and individuals and the target is depending on the business plan and prior year performance. In addition, the target setting were clearly made to determine the appropriate budget and targets should be achieved by a project. One of the interviewee stated that the target is increasing every year but the challenges also increase. Other interviewee added:

"The key performance indicators (KPI) is difficult to achieved because price of technology is become cheaper because of global competition but the KPI always increase based on past performance."

Most of the interviewees stated that the KPI need an effort to achieve it. One of them added that it also depends on the support team. In addition, the KPI can easily achieve if the process is clear and all employees give full commitment. In addition, in process of setting the KPI, the target must be reasonable and achievable by analysis the scenario. Top management also will question about why the employees choose that target and their decision are always based on fact.

\section{Performance evaluation and Rewards}

The system used by MMG to evaluate the performance of employees name MAPS. The BSC used based on the KPI is linked to the performance evaluation. Perceived of performance evaluation is different between levels of employees. For non-executive, their performance is evaluated by the executive and manager in their department. Level of non-executive always relies on their union. The union of non-executive makes sure the welfare of the employees is protected. Interviewees from the non-executive level are agreed that the achievement of the KPI is linked to the performance evaluation and they are satisfied on the process of performance evaluation.

From the perspectives of executive's level and assistant general manager's level, they perceived that the KPI is linked with performance evaluation. Responses from managers' level are varied. One of them stated that only $80 \%$ of KPI achievement is relates to performance evaluation. Others added that even though there a link between KPI and performance evaluation but it not linked to the bonus.

One of the managers stated:

"it depends on KPI. Even though you achieved the target, but when the evaluation goes to moderation from top management, it will be change. MMG have a belt system that limits the number of employees who get the best performance. The belt system has 4 levels and 4 is the best and 1 is the lowest. If they want to give 4 to one employees, they also have to give 1 to one employees. I am not so clear with the ranking. For example, myself, I get 90 for evaluation but the top management gives me only 2. This means that the excellent worker will get great performance evaluation. For me, there are not so clear regarding to moderation from top management. I think there a work politic in evaluation justification" 
In addition, one of the managers also stated that from her own experiences:

"The achievement of the KPI in my own region is very good so I help other region to achieve their KPI but when the performance evaluation made, the other region inform that they get a better evaluation than me. This is not fair and I think that the KPI used is not link with the bonus."

The performance evaluation in MMG also always associated with the bell curve system by the interviewees. In the bell curve system, the performance evaluation rated the employees majority on average. The system limits the number of employees that get the excellent rating of the performance. As stated by one of the interviewees:

"...in the bell curve system, if the group do not achieved the target, they have to choose some of their members as a nonperformance rated. After assessment by our superior, the evaluation will go to the moderation by the top management. After moderation, the evaluation will be change and the rating will be resulted."

In addition to the bell curve, one of the interviewee stated that :

"Throughout my work here, KPI is only on paper. Although KPI show the improvement, it is not necessarily true. There are a lot of political games in work in this evaluation. Evaluation also depends on the boss and the boss sometimes also forced by top management to follow orders from them. KPI is a nice concept, but the way it is implemented here is less successful."

In summary, the employees in MMG perceived different opinion on the relationship between KPI and performance evaluation.

The employees in MMG will be given the rate of 1 to 4 for their performance evaluation. 1 is the lowest and 4 is the highest. The performance evaluation rate will affect the bonus received and annual increment. From non-executive level, the bonus received and annual increment for each range is not so different compared to other level. This level is protected by the union and there is no big issues regarding rewards and penalties.

All the managers are agreed that performance evaluation will link to the bonus received but most of them are not so agreed on how the top management give the moderation and majority of them are not agree with the bell curve system that being used by MMG. They also stated that there are political games when it came to the bonus and also depends on evaluators.

The process of information regarding their performance evaluation is started from the KPI setting, and then evaluation based on their KPI achievement. The evaluation of the employees is a face to face, the superior will give mark to their subordinates and their subordinates will agree or argue with reason if they have any issues. Then the subordinates will agree and sign the evaluation form. The evaluation will go to the moderation by top management and they will give the result by using rating 1 until 4 . 1 is not perform and will not receive any bonus, 2 is normal, 3 more than normal and 4 is excellent. The information regarding to evaluation after moderation and rated, will be available for each employees. The information are private and confidential and only available for their self.

\section{Used and Controls}

From the used and control perspective, the key success factors and measures from interviewees are varied. The responses from the interviewees regarding key success factors revealed broad and ranging views on what such factors were for MMG. Key success factors included product, technology, process, leadership and staff. From the product, the respondents reveal that the product differentiation must be up to date and meet the technology to make sure MMG can be market leader, have competitive advantage and meet the needs of the customers. The way to market the product also important and the needs of innovative and inventive to ensure successful. In addition, the strength of MMG is that they are investing heavily on international market, so they can control pricing and give competitive price. However, they also have many vendor in venturing new products, supposedly they have to give full effort to reduce the dependency on the outsiders.

From the process perspective, the flow and step of the process must be clear to become good system and this will influenced the performance of the employees. Other key success factor is leadership. Leadership is important, the management have to be clear and the employees will easy to follow and commit. The top management also have to communicate a clear vision and mission in order to attract the full commitment from the employees. The commitment, accountability and responsibility of the employees and entire organisation unite to achieve vision and mission of MMG are also the key success factor for MMG. One of the interviewee also added that unite together to achieve good performance and BSC is a tool that can combine it all. Other factors that believed to be key success factor are financial and internal business process. They all believed that the key success factors are included in KPI.

While the above factors did not seem to contradict the overarching goals of MMG, the key success factors appeared to be diverse than expected. As stated on their annual report in 2012, the main key success factors in MMG are the strategy and execution of the strategy. In line with being Malaysia's leading utilities Provider, they have introduced and implemented a Performance Improvement Programme (PIP 2.0) to embrace their customers' needs through constant innovation and execution excellence.

Most of the interviewee stated that the KPI used is a good tool to guide employees work and control employees' behaviour. BSC give guidelines through KPI. However, one of the managers thought that the employees have to be guide and control personally even though they have BSC especially for non-executive. One of the managers added that 
when the KPI is not so linked with the performance evaluation, the motivation to perform better will be decrease.

There are many recommendations from the interviewees to improve the BSC in MMG which include automatic promotion based on performance and improve reward system. Some of the interviewee stated about unfair performance evaluation because of political games, biased and favouritism by the evaluators, moderation from top management and bell curve system.

\section{B. The Impact of KPI on employees behaviour}

The impact of BSC on employees behaviour is examined by the question asked whether the system used in MMG effect their behaviour and performance. The behaviour of employees can be divided into three (theory of planned behaviour) includes attitude, norm and perceived behavioral control.

From the attitude perspectives, there are positive and negative attitude of employees in implementing performance management system. From positive side attitide of employees in MMG, majority of them perceived that the performance management system used in MMG make their work become easier, manageble and focused. From positive perspective among employees, they give their effort to achieve the KPI target to get the reward. The motivation for them is the reward which is bonus. In negative influences attitude of employees are some of the employees become selfish in order to get the reward in the used of performance management. They may do political games in order to achieve what they want. They tend to influence their superior by make a good story about them and pretend to be good. They may also influence the KPI by stated low standard of achieving KPI.

Norm refers to the belief about whether most people approve or disapprove of the behaviour. It relates to a person's beliefs about whether peers and people of importance to the person think he or she should engage in the behaviour. From the perspectives of norms, the employees tend to give its commitment and full effort based on work culture and peer recognitions. In MMG, employees tend to give their effort in order to survive in the work KPI culture where all employees want to achieved the KPI. Employees in MMG influenced by the monitoring by the superior and in order to get intention by their superior, some of them are pretend to be good only in front of the superiors and flatterers their superiors in order to get good performance evaluation.

From the perspectives of perceived behavioural control, the employees in MMG is influenced by the perception on how easy the used the performance management system. The training is provided to employees in introducing new system. The employees do not have problem in using the system, but they perceived unfair when relates to performance evaluation and they may influenced the system to influenced the result.

The used of BSC in MMG is started from 1996. The used of KPI is become routine and work culture among the employees. At the same time, the used of BSC become bad work culture. BSC used make employees become selfish and want a highly achieving KPI targets as they are relate to the assessment of the performance and hence influence the bonus received. BSC used also become a political games among employees. They also want to get a recognition from the superior.

In addition, many employees are not satisfied with the moderation from top management and the bell curve system. These are resulted the decreased motivation of their work. When they feel injustice occurs, this will lead to job performance and work commitments will be reduced. In more severe cases, employees will begin to lose belief in the company and then quit their job and less of a contribution to the company's success.

\section{DISCUSSION AND CONCLUSION}

This session consists of the two main parts which is directly linked to the aims of the study. This paper discusses the use of KPI in MMG and then examines the influences of employees behavior in implementing performance management system in MMG. The performance management system today is very important to the organisations in order to be successful. In Malaysia, performance in GLCs always the main concern because they really influences the economy in Malaysia. In order to transform the GLCs to transform them into high-performing entities, the government introduce GLCT program and the first initiatives is to intensify performance management.

This findings of the study showed that the MMG have a good systems but the implementation have a problem from the behavioural perspectives of the employees. The systems also have a flaw when it relates to performance evaluation. Most of the interviewees are not satisfied with the bell curve system. They think that the system is unfair.

This study also wants to understand the employees' behaviour in implementing $\mathrm{BSC}$ as a performance management. Based on the discussion on the impact of employees' behaviour, the KPI actually influenced the employee's behaviour in positive and negative manner.

This research has several limitations that need to be addressed. This study adopts an interpretive case study method. Hence, the study is limited to the theoretical generalisations based on the findings. The use of a case study methodology for the study limits its generalization to situations or organisations dissimilar from the case studied (Gomm, Hammersley, \& Foster, 2000). While the findings may not be fully generalizable outside the GLC organisations but the description of the concepts in the study have the potential to make this study important for future research on management accounting. Hence, the results of the study cannot be taken out of context-a unique GLC in Malaysia, listed and regulated industry. The result could then be compared against the current study to provide a better understanding of the use of KPI in GLCs brought by the GLCT programmed. 
Case study method is known for having some limitations on its part, including lack of scientific rigor, research bias, overidentification with particular occupations or work settings and the inability to consider all possible influences on the researcher of the case (Luck, Jackson, \& Usher, 2006; Greenwood \& Lowenthal, 2005). Therefore this study have taking into consideration all of the possible biases identified through the analysis process and the writing process.

Last, the issue of justice, motivation and trust and power also could provide interesting insights into the process of using KPI in MMG. However, these concepts have not been sufficiently explained and understood in this thesis due to the time constraints.

Despite its limitations, this study has a potential value for carrying out a further study. The finding in this research will give evidence on KPI used in Malaysian GLCs. More study is needed in comparing the practices of Malaysian GLCs with other GLCs from other countries and with the nonGLCs. More studies can be made in replication to other organisations such as non-GLCs, small and medium enterprise, public services, non-profit organisation and financial institutions.

\section{REFERENCES}

Andon, P., Baxter, J., \& Chua, W. F. (2007). Accounting change as relational drifting: A field study of experiments with performance measurement. Management Accounting Research, 18(2), 273-308. doi:10.1016/j.mar.2006.06.007

Ayedh, A. M. (2007). Performance measurement practices in the Malaysian companies: An exploratory study. International Islamic University Malaysia.

Feng, F., Sun, Q., \& Tong, W. H. S. (2004). Do governmentlinked companies underperform? Journal of Banking \& Finance, 28(10), 2461-2492. doi:10.1016/j.jbankfin.2003.10.012

Goodpasture, J. C. (2003). Quantitative methods in project management. Boca, Raton, FL, USA: J. Ross Publishing.

James, W. (2009). Rationality, institutionalism and accounting change. Understanding a performance management system within an Australian public sector entity. Journal of Accounting \& Organizational Change, 5(No. 3), 362-389.

Kaplan, R. S., \& Norton, D. P. (1992). The Balanced Scorecard - Measures That Drive Performance. Harvard Business Review, (January-February), 9.

Kaplan, R. S., \& Norton, D. P. (1996). Linking the Balanced Scorecard to Strategy. California Management Review, 39(No.1 Fall), 27.

Kaplan, R. S., \& Norton, D. P. (2000). Having Trouble with Your Strategy? Then Map It. Harvard Business Review, (September-October), 10.
Mansor, N., Bahari, A., \& Justine, J. (2008). A StrategyBased Key Performance Indicators and Firm's Performance: The Experience of Government-Linked Companies in Malaysia. International Journal of Knowledge, Culture and Change Management, 8(2), 93-104.

NEAC. (2010). Re-engineering the government' role in business, (September), 1-39.

Norhayati, M. A., \& Siti-Nabiha, A. K. (2009). A case study of the performance management system in a Malaysian government linked company. Journal of Accounting \& Organizational Change, 5(No. 2), 243276.

Northcott, D., \& Smith, J. (2011). Managing performance at the top: a balanced scorecard for boards of directors. Journal of Accounting \& Organizational Change, 7(1), 33-56. doi:10.1108/18325911111125531

Othman, R. (2006). Balanced scorecard and causal model development: preliminary findings. Management Decision, 44(No. 5), 13.

Othman, R., Domil, A. K. A., Senik, Z. C., Abdullah, N. L., \& Hamzah, N. (2006). A Case Study of Balanced Scorecard Implementation in a Malaysian Company. Journal of Asia-Pacific Business, 7(No. 2), 18.

PCG. (2005). Blue Book: Intensfying Performance Management. Blue Book Version 2.

PCG. (2008, December). Special focus on "people and performance'. Minda Newsletter Issues No. 1, 28.

Sharma, U., Lawrence, S., \& Lowe, A. (2010). Institutional contradiction and management control innovation: A field study of total quality management practices in a privatized telecommunication company. Management Accounting Research, 21, 14.

Sundin, H., Granlund, M., \& Brown, D. A. (2010). Balancing Multiple Competing Objectives with a Balanced Scorecard. European Accounting Review, 19(2), 203-246.

Verzola, A., Bentivegna, R., Carandina, G., Trevisani, L., Gregorio, P., \& Mandini, A. (2009). Multidimensional evaluation of performance: experimental application of the balanced scorecard in Ferrara university hospital. Cost Effectiveness and Resource Allocation, 7:15, 8.

Zin, N. M., \& Sulaiman, S. (2011). Government-linked Companies Blue Book ( GLCs Blue Book ) as a complement to Balanced Scorecard (BSC) in the Government-Linked Companies transformation program. In 2010 International Conference on Business and Economics Research (Vol. 1, pp. 294297). 
Appendix 1

Table 1 List of Interviewees

\begin{tabular}{|c|c|c|c|}
\hline $\begin{array}{l}\text { Inter } \\
\text { view } \\
\text { ee }\end{array}$ & Position & $\begin{array}{l}\text { Departm } \\
\text { ent }\end{array}$ & $\begin{array}{l}\text { Job description } \\
\text { and involvement in } \\
\text { BSC }\end{array}$ \\
\hline 1 & $\begin{array}{l}\text { Assistant } \\
\text { General } \\
\text { Manager }\end{array}$ & Strategy & $\begin{array}{l}\text { Assist the Executive } \\
\text { Officer in alignment } \\
\text { and cascading the } \\
\text { KPI. }\end{array}$ \\
\hline 2 & Manager & Strategy & $\begin{array}{l}\text { Assist issues } \\
\text { regarding KPI } \\
\text { between strategy } \\
\text { and human } \\
\text { resources. }\end{array}$ \\
\hline 3 & Manager & $\begin{array}{l}\text { Sales } \\
\text { Support }\end{array}$ & $\begin{array}{l}\text { Sales support, } \\
\text { proposed functional } \\
\text { KPI. }\end{array}$ \\
\hline 4 & Manager & $\begin{array}{l}\text { Sales } \\
\text { Support }\end{array}$ & $\begin{array}{l}\text { Sales support, } \\
\text { proposed functional } \\
\text { KPI. }\end{array}$ \\
\hline 5 & Manager & $\begin{array}{l}\text { Sales } \\
\text { Support }\end{array}$ & $\begin{array}{l}\text { Managing global } \\
\text { account, services } \\
\text { agreement and } \\
\text { billing. }\end{array}$ \\
\hline 6 & $\begin{array}{l}\text { Non- } \\
\text { Executive }\end{array}$ & $\begin{array}{l}\text { Human } \\
\text { Resource } \\
\mathrm{S}\end{array}$ & $\begin{array}{l}\text { Administration and } \\
\text { conduct events. }\end{array}$ \\
\hline 7 & Manager & $\begin{array}{l}\text { IT } \\
\text { Services }\end{array}$ & $\begin{array}{l}\text { IT technical support } \\
\text { for staff. Set KPI } \\
\text { and evaluation for } \\
\text { executive and non- } \\
\text { executive. }\end{array}$ \\
\hline 8 & Executive & $\begin{array}{l}\text { IT } \\
\text { Services }\end{array}$ & $\begin{array}{l}\text { Assist IT system, } \\
\text { monthly report IT } \\
\text { request, and } \\
\text { community change } \\
\text { management. Set } \\
\text { KPI for non- } \\
\text { executive. }\end{array}$ \\
\hline 9 & $\begin{array}{l}\text { Non- } \\
\text { Executive }\end{array}$ & $\begin{array}{l}\text { IT } \\
\text { Services }\end{array}$ & IT services for Staff. \\
\hline 10 & $\begin{array}{l}\text { Assistant } \\
\text { General } \\
\text { Manager }\end{array}$ & Sales & $\begin{array}{l}\text { Set the KPI for the } \\
\text { manager and unit, } \\
\text { do sales budget. }\end{array}$ \\
\hline 11 & Manager & $\begin{array}{l}\text { Global } \\
\text { and } \\
\text { Wholesal } \\
\text { e }\end{array}$ & $\begin{array}{l}\text { Proposed KPI for } \\
\text { strategy department. }\end{array}$ \\
\hline 12 & Executive & $\begin{array}{l}\text { Training- } \\
\text { IT }\end{array}$ & $\begin{array}{l}\text { Control and assist } \\
\text { training for staff and } \\
\text { set the KPI and } \\
\text { evaluate the }\end{array}$ \\
\hline
\end{tabular}

\begin{tabular}{|c|c|c|c|}
\hline & & & $\begin{array}{l}\text { performance for the } \\
\text { non-executive, }\end{array}$ \\
\hline 13 & Executive & $\begin{array}{l}\text { Administ } \\
\text { ration-IT }\end{array}$ & $\begin{array}{l}\text { Administration } \\
\text { work and set the } \\
\text { KPI and evaluate } \\
\text { the performance for } \\
\text { the non-executive }\end{array}$ \\
\hline 14 & Executive & $\begin{array}{l}\text { Compete } \\
\text { ncy-IT }\end{array}$ & $\begin{array}{l}\text { Assess the } \\
\text { employees } \\
\text { competency and set } \\
\text { the KPI and } \\
\text { evaluate the } \\
\text { performance for the } \\
\text { non-executive }\end{array}$ \\
\hline 15 & Manager & $\begin{array}{l}\text { Human } \\
\text { Resource } \\
\text { s }\end{array}$ & $\begin{array}{l}\text { Assist human } \\
\text { capital and directly } \\
\text { involved in } \\
\text { managing Balanced } \\
\text { Scorecard in the } \\
\text { division. }\end{array}$ \\
\hline 16 & AGM & $\begin{array}{l}\text { Global } \\
\text { and } \\
\text { Wholesal } \\
\text { e }\end{array}$ & $\begin{array}{l}\text { Set and evaluate } \\
\text { KPI for } 3 \text { managers } \\
\text { and } 3 \text { assistant } \\
\text { manager. }\end{array}$ \\
\hline 17 & Executive & $\begin{array}{l}\text { Finance- } \\
\text { IT }\end{array}$ & $\begin{array}{l}\text { Assist and control } \\
\text { general expenditure } \\
\text { for the division and } \\
\text { set the KPI and } \\
\text { evaluate the } \\
\text { performance for the } \\
\text { non-executive. }\end{array}$ \\
\hline 18 & Executive & $\begin{array}{l}\text { Finance- } \\
\text { IT }\end{array}$ & $\begin{array}{l}\text { Assist and control } \\
\text { general expenditure } \\
\text { for the division and } \\
\text { set the KPI and } \\
\text { valuate the } \\
\text { performance for the } \\
\text { non-executive. }\end{array}$ \\
\hline 19 & Manager & $\begin{array}{l}\text { Mobility } \\
\text { and } \\
\text { Manage } \\
\text { ment } \\
\text { Global } \\
\text { and } \\
\text { Wholesal } \\
\text { e }\end{array}$ & $\begin{array}{l}\text { Support function } \\
\text { and human } \\
\text { resources, and } \\
\text { proposed KPI for } \\
\text { the division and } \\
\text { individual. }\end{array}$ \\
\hline 20 & Manager & Finance & $\begin{array}{l}\text { Manager account } \\
\text { payable processing } \\
\text { and set and evaluate } \\
\text { KPI for executives } \\
\text { and non-executives. }\end{array}$ \\
\hline
\end{tabular}

